VerjaAl, A. \& Timmermans van den Bos, H.C.C. (1967) Combined degeneration of the spinal cord due to deficiency of alimentary vitamin $\mathbf{B}_{12}$. Journal of Neurology, NeuroSurgery and Psychiatry, 30, 464.

Walton, John N., KILOH, L.G., Osselton, J.W. \& Farrall, J. (1954) The electroencephalogram in pernicious anaemia and subacute combined degeneration of the cord. Electroencephalography and Clinical Neurophysiology, 6, 45.

WEST, E.D. \& ElLIS, F.R. (1966) The electroencephalogram in veganism, vegetarianism, vitamin $\mathbf{B}_{12}$ deficiency, and in controls. Journal of Neurology, Neuro-Surgery and Psychiatry, 29, 391.

Wokes, F., Badenoch, J. \& Sinclair, H.M. (1955) Human dietary deficiency of vitamin $\mathrm{B}_{12}$. American Journal of Clinical Nutrition, 3, 375.

WoKEs, F. (1956) Anaemia and vitamin $B_{12}$ dietary deficiency. Proceedings of the Nutrition Society, 15, 134.

\title{
Multiple unusual abnormalities in the electrocardiogram in myxoedema
}

\author{
J. DE SWIET \\ M.D., F.R.C.P. \\ Consultant Physician \\ East Glamorgan General Hospital, Glamorgan, Wales
}

DESCRIPTIONS of the electrocardiographic abnormalities in myxoedema have usually been confined to those of a sinus bradycardia, low-voltage QRS complexes, and T wave changes. Indeed, Wood (1968) described this combination as 'pathognomonic'. Additional changes, however, have been reported by other authors, including a prolonged Q-T interval (Hansen (1961), who also mentioned first degree heart-block), right bundle-branch block (Korth \& Schmidt, 1955), complete heart-block (Ibrahim, 1957) and supraventricular and ventricular paroxysmal tachycardia. A sinus tachycardia, slowing after specific treatment, and unexplained on any other grounds than myxoedema, does not appear to have been cited previously; while inverted $U$ waves also have not been described before in this disease.

\section{Case report}

A married woman of 53 was seen at out-patients with a 3-month history of fatigue, hoarseness, swollen hands, dry skin, puffy face, cramp in the feet, constipation, gain of a stone in weight, and recent cold intolerance. She had six children and had then been sterilized, but otherwise had an uneventful past history. Her menarche was at the age of $14 \frac{1}{2}$ and there was normal menstruation until the menopause at the age of 51. Particular questions were asked about possible anginal symptoms or other cardiac features, and none were elicited. There was no family history of any form of thyroid disease, diabetes mellitus, or pernicious anaemia, and no drugs had been taken in the remote or immediate past.

On examination her weight was $63 \mathrm{~kg}$, height 1.5 $\mathrm{m}$, temperature $35.5^{\circ} \mathrm{C}$, pulse-rate 88 , and blood- pressure $130 / 80 \mathrm{mmHg}$. She appeared normally alert, but had slightly puffy eyelids, a rough and dry skin over her arms, and there was no palpable thyroid tissue. The relaxation phase of her ankle-jerks was clearly prolonged. The clinical diagnostic index score was +41 (Billewicz et al., 1969).

Investigations included: serum electrolytes: $\mathrm{Na}$ $138, \mathrm{~K} \mathrm{4.0,Cl} \mathrm{101,} \mathrm{total} \mathrm{CO}_{2} 25 \mathrm{mEq} / 1$; plasmace calcium $10.6,10.6$ and $10.5 \mathrm{mg} / 100 \mathrm{ml}$; blood urea? $45 \mathrm{mg} / 100 \mathrm{ml}$; protein-bound iodine (PBI) 1.4 and $1.6 \mu \mathrm{g} / 100 \mathrm{ml}$; serum cholesterol $428 \mathrm{mg} / 100 \mathrm{ml}$; $\mathrm{Hb} 14.2 \mathrm{~g} / 100 \mathrm{ml}$; leucocytes $6,700 / \mathrm{mm}^{3}$ with normal differential count; urinalysis n.a.d.; negative autoprecipitin test for thyroid autoantibodies. Xray of chest showed no pulmonary or cardiac abnormality.

The electrocardiogram (Fig. 1) showed a sinus tachycardia (rate 120 in lead 1), left axis, semihorizontal position, normal voltage, widespread broadly-inverted $U$ waves, and a prolonged $Q-T$ interval $(0.36 \mathrm{sec}$, the average for the rate being $0.28 \mathrm{sec}$ corrected).

After 6 weeks treatment with thyroxine the electrocardiogram (Fig. 2) showed reduction of the sinus tachycardia to a rate of 100 , a more horizontal position, increased voltage of all complexes generally, absence of $U$ waves, and a normal Q-T interval. Normality of the ankle-jerks reflected a general clinical improvement in all respects, at the time of the repeat electrocardiogram.

\section{Discussion}

The clinical diagnosis of myxoedema appears certain in this case, but the pre-treatment electrocardiogram would suggest that this diagnosis was 

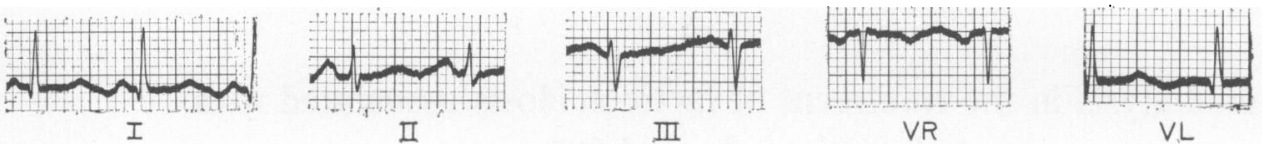

VR

VL

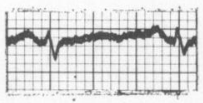

VF
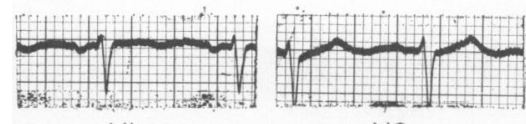

V2

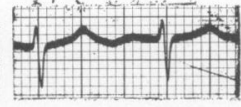

V3

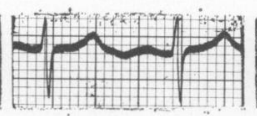

V4

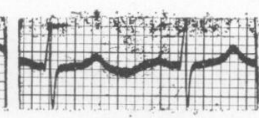

V5

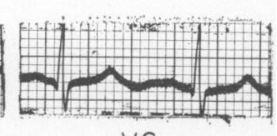

V6

FIG. 1. Electrocardiogram before treatment, showing sinus tachycardia, normal voltage, prolonged Q-T interval, and general widely inverted $U$ waves, best seen in lead 1, VL and V5.

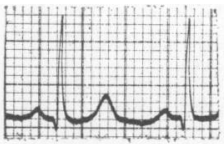

I

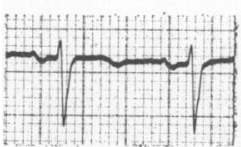

VI

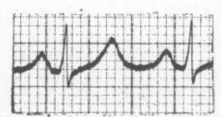

II

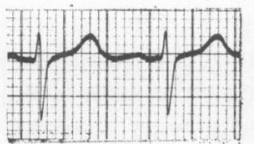

V2

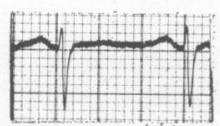

III

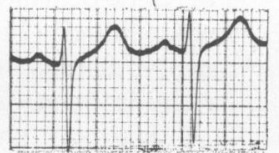

V3

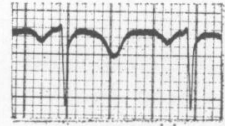

VR

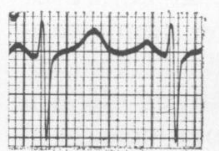

V4

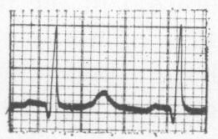

$\mathrm{VL}$

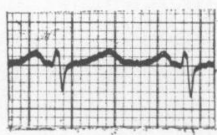

VF

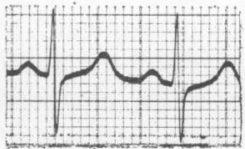

V5

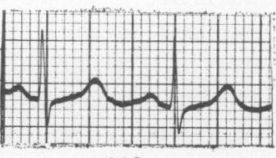

V6

Fig. 2. Electrocardiogram after 6 weeks treatment with thyroxine, showing 'paradoxical' reduction in heart rate, increased voltage, normal $Q-T$ interval and absence of $U$ waves.

most unlikely. While Williams (1968) mentions that patients with myxoedema may complain of nervousness and palpitation implying a possibility of thyrotoxicosis, it must be extremely rare to record a sinus tachycardia of 120 in an otherwise classical case of myxoedema, as here; further, the slowing of this tachycardia with treatment is surely 'paradoxical' as a response. In an analysis of electrocardiographic patterns in hypothyroid heart disease Douglas \& Samuel (1960) studied the heart rates in forty-four cases before treatment, and found a maximum rate of 90 beats/min, rising after treatment to a maximum of 120 . In the standard leads of their cases $38 \%$ showed low voltage, and in the precordial leads only $30 \%$ pre-treatment, and this does suggest that low voltage complexes occur considerably less frequently than is generally supposed. While they found a prolonged (corrected) Q-T interval in $46 \%$ of cases, they concluded that if this finding was due to hypothyroidism, it was irreversible within the time period covered by their study, but it was reversed in the present case. Regarding the $U$ wave, they found it present (without further comment) in $26 \%$ of ninety-two cases, and in $17 \%$ after treatment. Apart from isolated normal findings, negative $U$ waves have previously only been described in primary myocardial disorders such as angina, left ventricular hypertrophy, and cardiac infarction. Recently (de Swiet, 1969) a case of subarachnoid haemorrhage was described in which negative $U$ waves appeared, and the further finding of this abnormality in the present case (together with its disappearance on treatment) suggests that its occurrence is probably wider in range than hitherto supposed.

\section{References}

Billewicz, W.Z., Chapman, R.S., Crooks, J., Day, M.E., Gossage, J., Wayne, Sir E. \& Young, J.A. (1969) Statistical methods applied to the diagnosis of hypothyroidism. Quarterly Journal of Medicine, 38, 255.

Douglas, A.H. \& Samuel, P. (1960) Analysis of electrocardiographic patterns in hypothyroid heart disease. New York State Journal of Medicine, 60, 2227.

Hansen, J.E. (1961) Paroxysmal ventricular tachycardia associated with myxoedema. American Heart Journal, 61, 692.

IвRAHIM, M. (1957) Myxedema heart. Lancet (Minneapolis), $77,114$.

KoRTH, C. \& Schmidt, J. (1955) Neue Beobachtungen zum 'Myxödemherzen'. Deutsches Archiv für Klinische Medizin, $202,437$.

DE SwIET, J. (1969) Abnormal U waves in the electrocardiogram in subarachnoid haemorrhage. British Heart Journal, 31, 526.

Williams, R.H. (1968) Textbook of Endocrinology, 4th edn, p. 240. W. B. Saunders, Philadelphia.

Wood, P. (1968) Diseases of the Heart and Circulation, 3rd edn, p. 1024. Eyre \& Spottiswoode, London. 